Gut, 1977, 18, 303-310

\title{
Effect of atropine and proximal gastric vagotomy on the acid response to fundic distension in man
}

\author{
U. GRÖTZINGER, S. BERGEG ÅDH, AND L. OLBE \\ From the University of Göteborg, Department of Surgery, II, Sahlgren's Hospital, Göteborg, Sweden
}

SUMMARY In four healthy subjects and in 12 patients with duodenal ulcer (DU), graded balloon distension of the gastric fundus and body caused increments in acid output related to the distension volumes. The mean peak distension response amounted to about $50 \%$ of the mean peak acid output $\left(\mathrm{PAO}_{\mathrm{pg}}\right)$ evoked by intravenous infusion of pentagastrin in a dose of $300 \mu \mathrm{g} / \mathrm{h}$, eliciting maximum observed secretory response. During distension with the largest balloon volume, $1.0 \mathrm{mg}$ atropine injected intravenously significantly depressed the acid secretory rate, the median inhibition amounting to about $80 \%$. In two patients with DU, $2.5 \mathrm{mg}$ atropine completely abolished acid secretion during fundic distension. In nine subjects with DU, complete proximal gastric vagotomy profoundly depressed the secretory responses to graded fundic distension, eliminating the acid response to the smallest balloon volume used. A slight, but significant, response to the largest distension volume persisted after complete vagotomy. Incomplete proximal gastric vagotomy was found to reduce only moderately the distension responses in five patients, and the peak acid response to fundic distension as related to $\mathrm{PAO}_{\mathrm{pg}}$ remained unchanged. In conclusion, distension of the gastric fundus and body in man stimulates acid secretion by means of an atropine-sensitive, presumably cholinergic, reflex mechanism and the findings after vagotomy are in agreement with the concept that this reflex mechanism is conveyed by both short intramural and long vagovagal pathways.

Distension of the stomach stimulates the parietal cells to secrete hydrochloric acid (Lim et al.,1925). In the dog, distension of the fundus and body of the stomach activates cholinergic oxynto-oxyntic reflexes which are conveyed by intrinsic and extrinsic neural pathways (Grossman, 1961, 1962; Preshaw, 1970a, b; Magee and $\mathrm{Hu}, 1975)$. The integrity of antral innervation has been found to be essential for the full secretory effect of fundic distension (Preshaw, 1970a). Recently, it has been shown that fundic distension causes liberation of gastrin from the alkaline pyloric antrum, probably via a vagovagal, oxynto-pyloric reflex (Debas and Grossman, 1975; Debas et al., 1975).

Balloon distension of the gastric fundus and body gives rise to considerable acid secretory rates in normal man as well as in duodenal ulcer patients (Grötzinger et al., 1976). The present investigation was undertaken to elucidate the mechanisms by which distension of the oxyntic gland area elicits gastric secretion of acid in man.

Received for publication 19 November 1976

\section{Methods}

SUBJECTS STUDIED

Healthy subjects

Four male students aged between 21 and 25 years with no history of gastrointestinal disease or other relevant illness volunteered to participate in the experiments.

\section{Patients with duodenal ulcer (DU)}

Twelve men (mean age 48 years, range 26-65 years) with chronic duodenal ulceration were examined in the atropine studies. Another group of 14 male subjects with DU (mean age 41 years, range 21-58 years) was studied before and after proximal gastric vagotomy. The diagnosis was made by endoscopy and/or barium meal examination and confirmed at operation. In no patient was there any evidence of gastric outlet obstruction.

The purely scientific interest of the experiments was emphasised and informed consent was obtained from each subject. The investigation was approved 
by the Ethical Committee of the Faculty of Medicine, University of Göteborg.

\section{EXPERIMENTAL PROCEDURES}

Details of the methods for determining acid output and of the fundic distension procedure used in this study have been given elsewhere (Grötzinger et al., 1976). Any anticholinergic medication was discontinued two days before the tests. Experiments were performed in random order on separate days within a period of three weeks. After an overnight fast, the subjects were seated in a semirecumbent position and a double lumen nasogastric tube was passed and its tip positioned in the gastric antrum as ascertained by fluoroscopy. Residual gastric contents were aspirated and discarded. Throughout the experiments, phenol red in water $(8 \mathrm{mg} / \mathrm{l})$ was infused into the stomach through a thin polyethylene tube at a constant rate of $225 \mathrm{ml} / 15 \mathrm{~min}$. Gastric contents were continuously aspirated using an electrically driven suction pump giving intermittent negative pressure once per second.

Graded distension of the gastric fundus and body was achieved by attaching to the nasogastric tube a thin-walled rubber balloon which was slowly inflated with air to selected volumes. Its position was frequently checked by fluoroscopy. Six hundred millilitres was chosen as the maximal distension volume as it had been found to evoke the highest acid output attainable with fundic distension. Larger balloon volumes were associated with pain or nausea and dampened the secretory rate.

In the pentagastrin infusion tests, gastrin pentapeptide (Peptavlon, ICI) was given intravenously at constant rates of $90 \mu \mathrm{g} / \mathrm{h}$ for 45 minutes followed by $300 \mu \mathrm{g} / \mathrm{h}$ for another 60 minutes.

The continuously aspirated gastric contents were divided into 15 minute samples and the volume and pH were recorded. From each sample a $100 \mathrm{ml}$ aliquot was titrated against $0.1 \mathrm{~mol} / 1 \mathrm{NaOH}$ to pH 7.0 on a Radiometer Autoburette. For each 15 minute sample the phenol red concentration was assessed spectrophotometrically. With the assumption that the marker solution and the gastric juice had mixed homogeneously, the percentage recovery of gastric contents could be estimated. This allowed the amount of acid secreted to be calculated. All values given below are corrected for pyloric losses. On the basis of the available data no allowance could be made in these calculations for duodenalgastric reflux.

Fundic distension and atropine (four healthy subjects, 12 DU patients)

Control experiments Basal secretion was recorded for at least $\mathbf{4 5}$ minutes. Graded fundic distension was performed with the balloon inflated to 150 , 300 , and $600 \mathrm{ml}$, each volume being maintained for one hour. The mean value of the last two 15 minute periods under basal conditions, during distension with 150,300 , and $600 \mathrm{ml}$, and in the one hour postdistension period was taken to represent the acid output during the corresponding part of the experiment. The mean of the two highest consecutive 15 minute values observed at any time during distension denotes the peak acid output elicited by fundic distension (PAO dist). The peak acid output after pentagastrin stimulation $\left(\mathrm{PAO}_{\mathrm{pg}}\right)$ is defined in an analogous fashion.

Experiments with atropine Acid secretion was collected during a one hour basal period and during fundic distension with $300 \mathrm{ml}$ for one hour. The distension volume was then increased to $600 \mathrm{ml}$ and, at the same time, $1.0 \mathrm{mg}$ atropine sulphate was injected intravenously. In two DU patients the atropine dose was $2.5 \mathrm{mg}$. The secretory rate was recorded for a further two hours after which distension was discontinued. Basal secretion, $300 \mathrm{ml}$ response, and the acid output during the first and second hour after atropine with $600 \mathrm{ml}$ distension are given by the means of the two last 15 minute values in the corresponding parts of the experiment. The minimum post-atropine secretory rate is defined as the mean of the two lowest consecutive 15 minute periods observed at any time after the injection of atropine.

Fundic distension before and after proximal gastric vagotomy

In 14 DU patients, graded fundic distension with 150,300 , and $600 \mathrm{ml}$ and pentagastrin infusion tests were carried out as described above before and after proximal gastric vagotomy. Experiments were done not earlier than one month after operation. In postoperative insulin tests, basal secretion was collected during at least 90 minutes. Insulin $(0.2 \mathrm{IU} / \mathrm{kg}$ bodyweight) was given by rapid intravenous injection and the secretory rate was recorded for at least two hours. All patients displayed clear symptoms of hypoglycaemia. Both acidity and acid output were determined for each 15 minute period. Basal secretion was expressed as the mean of all 15 minute values before insulin. The peak acid response to insulin $\left(\mathrm{PAO}_{\text {ins }}\right)$ denotes the highest 15 minute value observed, and $\triangle \mathrm{PAO}_{\text {ins }}$ is the highest post-insulin increase over mean basal ( $\mathrm{mmol} / 15 \mathrm{~min})$. These data as well as the highest consecutive hourly secretion rates observed under basal conditions and after insulin were used for interpretation of the tests by applying multiple criteria (Hollander, 1948; Ross and Kay, 1954; Bachrach, 1962; Stempien, 1962; 
Bank et al., 1967; Gillespie et al., 1972). When two or more of the seven criteria (Table 1) were fulfilled the test was considered positive.

SURGICAL PROCEDURE

Patients were free of symptoms at the time of elective surgery. Proximal gastric vagotomy without a drainage procedure (PGV) was performed. Denervation of the lesser curvature was guided by anatomical landmarks preserving two branches of each of Latarjet's nerves and leaving the distal 6-7 $\mathrm{cm}$ of the antrum vagally innervated. The lowermost $4-5 \mathrm{~cm}$ of the oesophagus was cleared of vagal strands and the fundus was dissected free of its attachments to the diaphragm and hiatus. No complication was encountered.

\section{STATISTICAL EVALUATION}

In each group of distension experiments, the significance of differences between steps was examined by analysis of variance followed by Sheffe's test for multiple comparison (Morrison, 1967). These methods as well as Student's $t$ test and the MannWhitney U test were applied when assessing the effects of atropine or PGV in a given group or when comparing groups.

Table 1 Acid secretory data and interpretation of postoperative insulin tests using multiple criteria in 14 patients with DU subjected to proximal gastric vagotomy

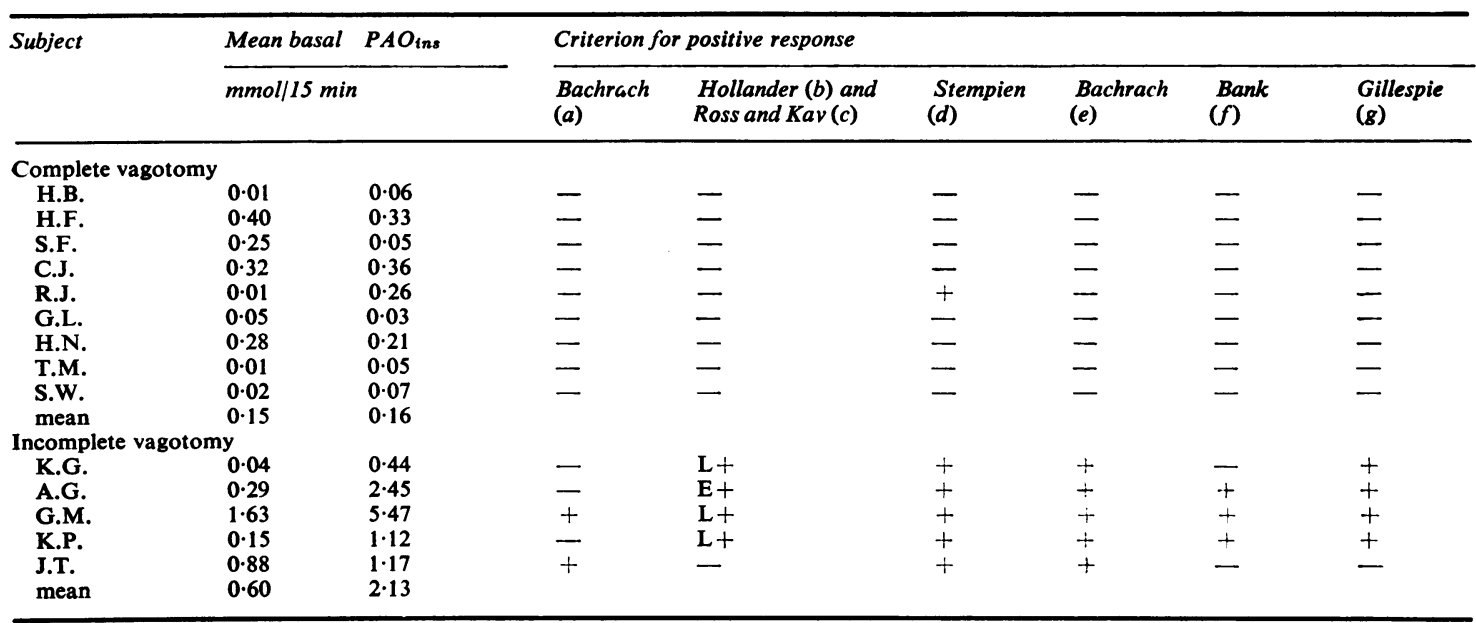

- insulin test negative, + insulin test positive, $\mathrm{E}+$ positive in first hour, $\mathrm{L}+$ positive in second hour

(a) Basal acid output $\uparrow 2 \mathrm{mmol} / \mathrm{h}$ (Bachrach, 1962)

(b) Acid concentration $\uparrow 20 \mathrm{mmol} / 1$ (Hollander, 1948)

(c) Early + : Hollander + in first hour after insulin, late + : Hollander + in second hour after insulin (Ross and Kay, 1964)

(d) Acid output $\uparrow 0.25 \mathrm{mmol} / \mathrm{h}$ (Stempien, 1962)

(e) Acid output $\uparrow 1.0 \mathrm{mmol} / \mathrm{h}$ (Bachrach, 1962)

(f) Acid output $\uparrow 2.0 \mathrm{mmol} / \mathrm{h}$ (Bank et al., 1967)

(g) Acid output $3 \times$ basal output (Gillespie et al., 1972)

Table 2 Effect of intravenous atropine on acid secretory response to fundic distension in four healthy subjects and 12 patients with $D U($ means $+S E M)$

\begin{tabular}{|c|c|c|c|c|c|c|}
\hline \multirow[t]{3}{*}{ Group } & \multicolumn{2}{|c|}{ Control experiment (without atropine) } & \multicolumn{3}{|c|}{ 600-ml distension + i.v. atropine } & \multirow{3}{*}{$\begin{array}{l}\text { Median } \\
\text { inhibition } \\
\text { lst } h \\
(\%)\end{array}$} \\
\hline & $P A O_{d i s t} \cdot 100$ & $600 \mathrm{ml}$ distension & Ist $h$ & $2 n d h$ & minimum & \\
\hline & \multicolumn{2}{|l|}{$\begin{array}{c}P A O_{p g} \\
(\%)\end{array}$} & \multicolumn{3}{|c|}{$(\mathrm{mmol} / 15 \mathrm{~min})$} & \\
\hline $\begin{array}{l}\text { Healthy subjects (4) } \\
1.0 \mathrm{mg} \text { atropine }\end{array}$ & $45 \cdot 0 \pm 7 \cdot 9$ & $4.35 \pm 0.71$ & $0.91 \pm 0.45$ & $0.84 \pm 0.35$ & $0.68 \pm 0.36$ & $82 \cdot 6$ \\
\hline $\begin{array}{l}\text { DU patients }(10) \\
1.0 \mathrm{mg} \text { atropine } \\
\text { DU patients }(2) \\
2.5 \mathrm{mg} \text { atropine }\end{array}$ & $51 \cdot 7 \pm 5 \cdot 2$ & $5.05 \pm 0.72$ & $1.42 \pm 0.44$ & $1.63 \pm 0.54$ & $1 \cdot 12 \pm 0 \cdot 40$ & $80 \cdot 7$ \\
\hline $\begin{array}{l}\text { K.H. } \\
\text { I.J. }\end{array}$ & $\begin{array}{l}67 \cdot 4 \\
46 \cdot 0\end{array}$ & $\begin{array}{l}7 \cdot 04 \\
5 \cdot 67\end{array}$ & $\begin{array}{l}0 \cdot 15 \\
0 \cdot 17\end{array}$ & $\begin{array}{l}0.02 \\
0.01\end{array}$ & $\begin{array}{l}0.01 \\
0.01\end{array}$ & $97 \cdot 5$ \\
\hline
\end{tabular}




\section{Results}

EFFECT OF INTRAVENOUS ATROPINE ON GASTRIC ACID RESPONSE TO FUNDIC DISTENSION

Both in healthy subjects and patients with DU, graded fundic distension with 300 and $600 \mathrm{ml}$ resulted in significant sequential volume related increments in acid output and the peak distension responses averaged about $50 \%$ of $\mathrm{PAO}_{\mathrm{pg}}$ (Table 2;

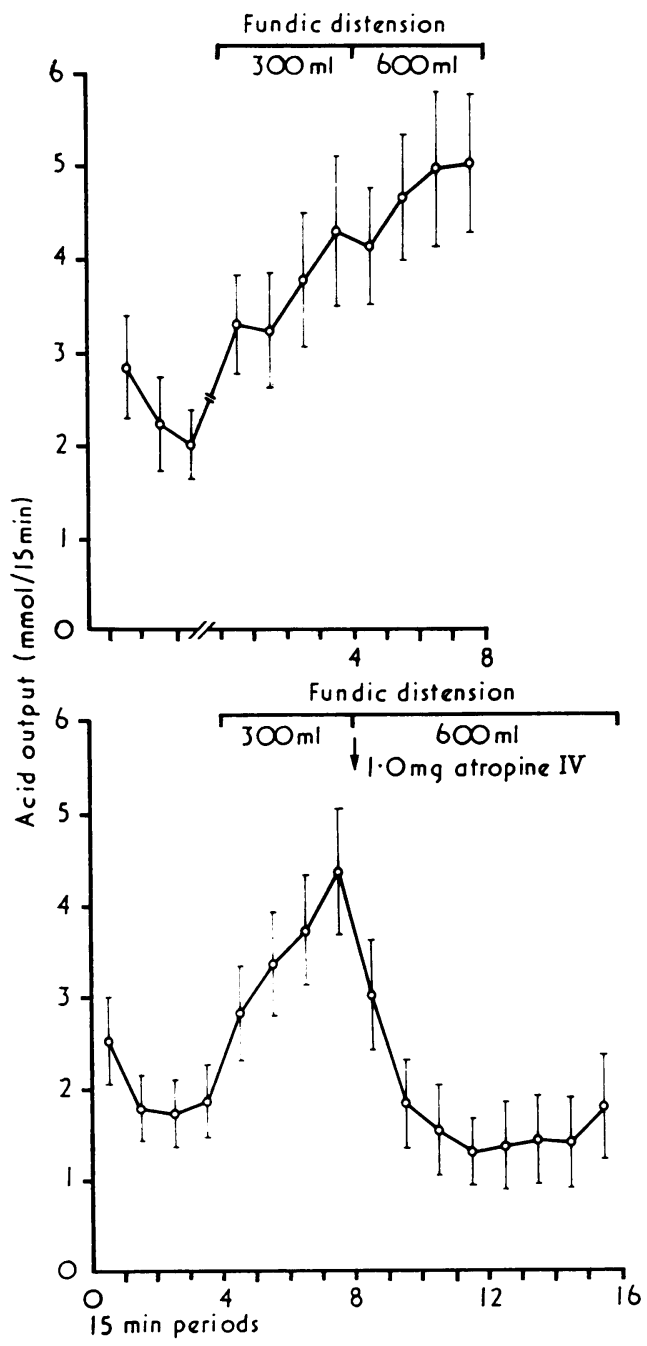

Fig. 1 Upper panel: effect of graded fundic distension upon acid secretion in control experiments on 10 patients with DU. Lower panel: intravenous atropine is shown to inhibit the acid response to fundic distension in the same subjects. The vertical bars indicate the standard errors of the means.
Fig. 1, upper panel). In the atropine studies, fundic distension with $300 \mathrm{ml}$ produced an acid output, equal to that observed in the control experiments. The subsequent intravenous injection of $1.0 \mathrm{mg}$ atropine significantly $(P<0.001)$ suppressed the secretory rate, in spite of the fact that the distending volume had been increased to $600 \mathrm{ml}$ (Fig. 1, lower panel). In both DU and healthy subjects, $1.0 \mathrm{mg}$ atropine caused a median inhibition of the acid response to $600 \mathrm{ml}$ distension by about $80 \%$ (Table 2). In two patients with DU, $2.5 \mathrm{mg}$ atropine, intravenously, completely abolished acid secretion during fundic distension (Table 2).

The mean phenol red recovery was 85 and $84 \%$ in the control and atropine experiments, respectively.

EFFECT OF PROXIMAL GASTRIC VAGOTOMY ON GASTRIC ACID RESPONSE TO GRADED FUNDIC DISTENSION

In 14 patients with DU, tests with graded fundic distension and intravenous infusion of pentagastrin were performed before and after PGV. According to the interpretation of the postoperative insulin tests the patients were divided into two groups of subjects considered to be completely, or incompletely, vagotomised (Table 1).

\section{COMPLETE VAGOTOMY}

Preoperatively, graded fundic distension with 150 , 300 , and $600 \mathrm{ml}$ resulted in a significant $(P<0.01)$ stepwise increase in acid output, although the difference between 300 and $600 \mathrm{ml}$ responses did not quite reach statistical significance (Figs. 2 and 3a). The mean PAO dist amounted to $5 \cdot 23 \mathrm{mmol} / 15 \mathrm{~min}$., corresponding to $52 \%$ of the peak pentagastrin response $(10.07 \mathrm{mmol} / 15 \mathrm{~min}$.). After operation, a uniform pattern of distension responses was observed in all subjects. PGV virtually abolished basal secretion and acid output during $150 \mathrm{ml}$ distension (median reductions 97 and $99 \%$, respectively). Only distension with $600 \mathrm{ml}$ caused a significant $(P<0.01)$ increase over basal levels after PGV. The peak distension response was significantly $(\mathrm{P}<0.001)$ reduced to a mean of $1.03 \mathrm{mmol} / 15 \mathrm{~min}$ or, on the average, $21 \%$ of the postoperative $\mathrm{PAO}_{\mathrm{pg}}$ (mean $5.15 \mathrm{mmol} / 15 \mathrm{~min})$. PGV reduced $P A O_{\text {dist }}$ to a significantly larger extent than $\mathbf{P A O}_{\mathrm{pg}}$ (median reductions 82.5 and $46.0 \%$, respectively; $P<0.01$ ).

The mean phenol red recovery in pre- and postoperative distension experiments was 85 and $90 \%$, respectively.

Insulin tests were carried out 1.5 months (median; range 1-2.5) after operation. The peak acid increase over mean basal output $\left(\triangle \mathrm{PAO}_{\text {ins }}\right)$ averaged $0.05 \pm 0.03(\mathrm{SEM}) \mathrm{mmol} / 15 \mathrm{~min}$. 


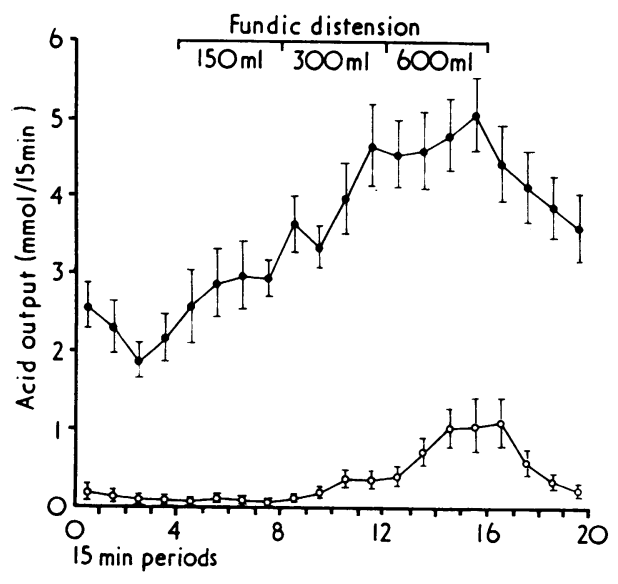

Fig. 2 The pattern of acid secretion evoked by graded fundic distension before $(--)$ ) and after $(\mathrm{O}-\mathrm{O})$ complete proximal gastric vagotomy in nine patients with $D U$. Vertical bars indicate the standard error of the means.

\section{Incomplete vagotomy}

Preoperative secretory data in five patients with DU who were judged to have incomplete vagotomies were very similar to those found in the nine completely vagotomised DU subjects, although the peak secretory fraction of $\mathbf{P A O}_{\mathrm{pg}}$ elicited by fundic distension tended to be numerically, but not significantly, higher (mean $63 \%$ ).

Proximal gastric vagotomy significantly $(\mathrm{P}<0.05)$ dampened basal secretion and the acid response to $150 \mathrm{ml}$ distension, while the responses to higher distension volumes were only slightly reduced (Fig. 3b). In all five patients a uniform pattern of response was observed. Numerically, the postoperative decreases corresponded with the reduction in basal acid output. After PGV, fundic distension elicited the same peak secretory fraction of the $\mathrm{PAO}_{\mathrm{pg}}$ (mean $60 \%$ ) as was found before operation, clearly showing that the reductions of distension- and pentagastrin-induced peak secretory rates were parallel. These decreases were significantly $(\mathrm{P}<0.01$ and $P<0.001$, respectively) smaller than those observed after complete vagotomy. The differences in fundic distension responses between subjects with incomplete and complete vagotomy are even more apparent when the distension responses are normalised in terms of preoperative and postoperative PAO $_{\text {pg }}$ (Fig. 4a and b).

The mean phenol red recovery in the fundic distension tests was 87 and $89 \%$ before and after vagotomy, respectively.

The median interval between operation and insulin tests was 6.5 months (range 1.5-7.5) and the mean $\triangle \mathrm{PAO}_{\text {ins }}$ amounted to $1.53 \pm 0.67(\mathrm{SEM}) \mathrm{mmol} / 15$ min. The peak insulin responses were significantly $(P<0.001)$ larger than those observed after complete vagotomy (Table 1).

\section{Discussion}

In both patients with DU and healthy subjects,
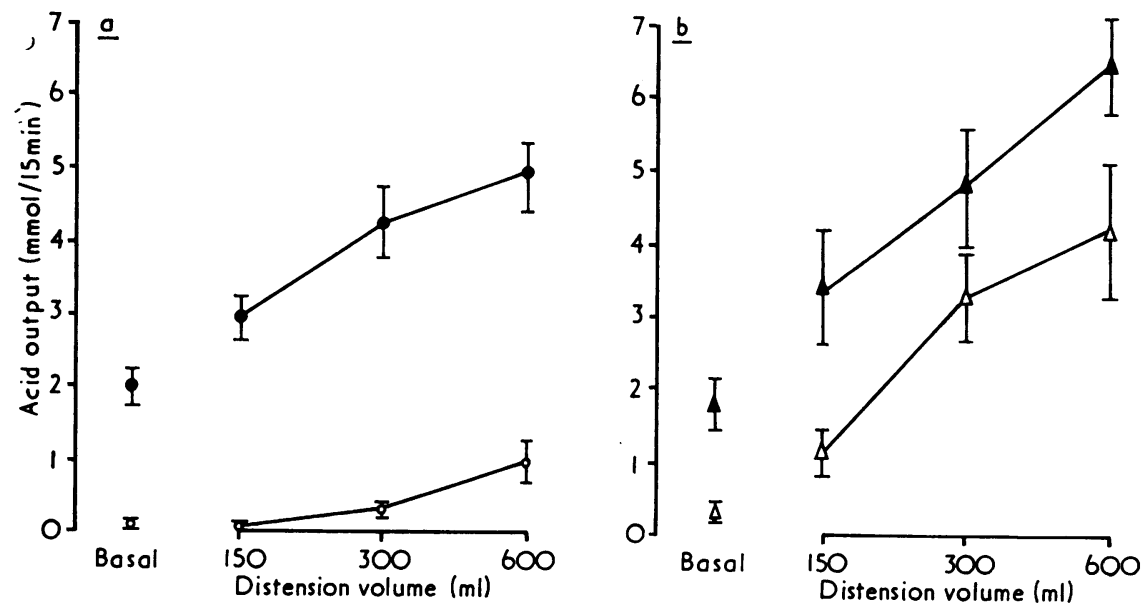

Fig. 3 The effect of proximal gastric vagotomy on the acid responses to graded fundic distension. Acid outputs were calculated as the means of the last two 15 minute values during different steps of the experiment. Each point denotes the mean of individual acid outputs and vertical bars indicate the standard errors of the means. a. Nine patients with $D U$ before $\left(O_{-}\right)$and after $(\bigcirc-\bigcirc)$ complete vagotomy. b. Five patients with DU before $(\Delta-\Delta)$ and after $(\triangle \longrightarrow \triangle)$ incomplete vagotomy. 

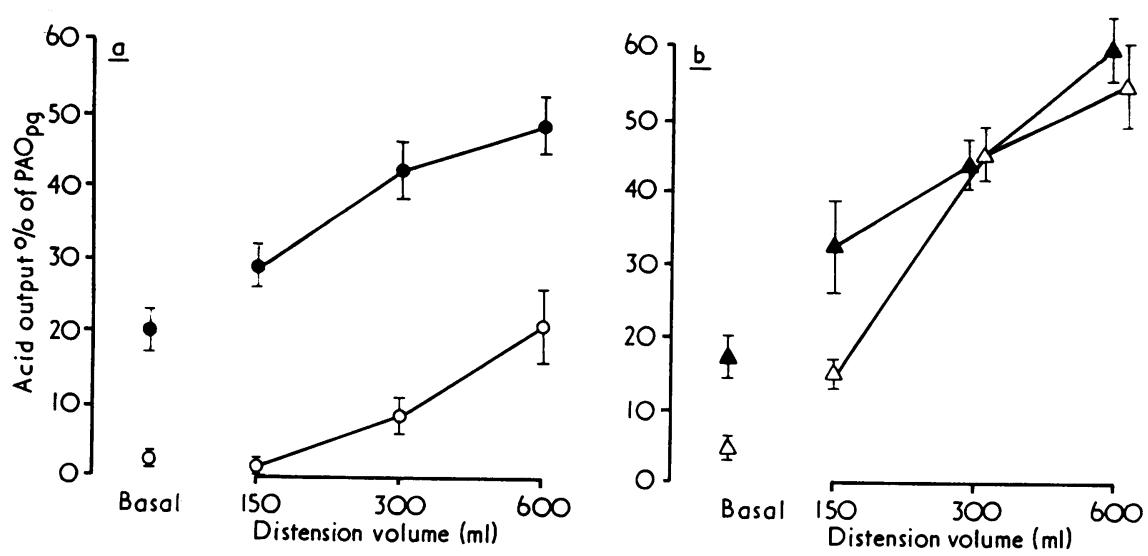

Fig. 4 Acid output in response to graded fundic distension expressed in per cent of the peak secretory rate evoked by intravenous pentagastrin as affected by proximal gastric vagotomy. The preoperative values are related to the individual peak pentagastrin responses found before operation and the postoperative data are based on the corresponding postoperative $P A O_{p g}$. For further explanation see legend to Fig. 3.

graded fundic distension evoked volume-related acid responses with a peak rate $\left(\mathrm{PAO}_{\text {dist }}\right)$ amounting to about $50 \%$ of the highest output observed during maximal pentagastrin stimulation $\left(\mathrm{PAO}_{\mathrm{pg}}\right)$. These results are in complete agreement with the findings in larger groups of subjects reported previously (Grötzinger et al., 1976). The mechanism by which fundic distension causes the parietal cells to secrete acid was found to be sensitive to atropine in a dosedependent manner. Intravenous atropine in a dose of $1.0 \mathrm{mg}$ inhibited the highest attainable secretory response to distension by about $80 \%$, and $2.5 \mathrm{mg}$ atropine completely abolished the acid output during distension with the highest balloon volume used. Cholinergic mechanisms are atropine-sensitive (Ambache, 1954), but the reverse statement is not necessarily true. Using atropine doses similar to those given in the present study, Konturek et al. (1968) found that the acid response to submaximal doses of pentagastrin or histamine were moderately, but significantly, reduced in DU patients. However, the responses to the largest doses of stimulants were unaffected by atropine, showing that pentagastrinstimulated acid secretion is fairly resistant to atropine. In contrast, the acid response to fundic distension can be completely blocked by atropine, favouring the view that the mechanism involved is predominantly cholinergic. This interpretation does not rule out the possibility that reflexly released gastrin contributes to the secretory response evoked by distension of the gastric fundus and body.

In nine of the 14 patients with DU subjected to proximal gastric vagotomy without drainage (PGV), insulin hypoglycaemia failed to stimulate acid secretion, suggesting that the parietal cell area had been completely vagally denervated. The preganglionic division of parasympathetic vagal fibres in PGV profoundly depressed basal secretion and acid output during fundic distension. However, after PGV a small, but significant, secretory response was obtained with fundic distension, probably being mediated by intramural cholinergic reflexes. It is open to question whether the intrinsic reflex mechanism involves the release of gastrin. The threshold volume for acid stimulation by distension was markedly increased after vagotomy (Figs 3a, 4a). The peak acid output during distension was significantly more suppressed than PAO $_{\mathrm{pg}}$ (reductions 82.5 and $46.0 \%$, respectively). These findings suggest that vagovagal reflexes participate and predominate in the mechanism by which mechanical activation of the human gastric fundus and body brings about acid secretion.

The present results in humans are consistent with earlier findings in the dog. Truncal vagotomy markedly reduced, but did not completely abolish the acid response to fundic distension in gastric fistula dogs provided with innervated antral pouches (Preshaw, 1970b). Graded distension of fundic pouches totally devoid of extrinsic innervation produced a volume-related acid output, which was augmented by a meal or exogenous humoral stimuli and completely blocked by atropine (Grossman, 1961). The evidence is in keeping with the concept that fundic distension in both dog (Grossman, 1962) and man acts via cholinergic local and vagovagal 
reflexes for acid secretion. Moreover, mechanical activation of the oxyntic gland area appears to have a very similar stimulatory potency in both man and dog, eliciting a peak secretory rate amounting to roughly $50 \%$ of the peak acid output evoked by exogenous gastrin in both species (Preshaw,1970a). This figure corresponds well with the values calculated for the maximal response to vagal activation by sham feeding in man (Knutson and Olbe, 1973; Mayer $e$ al., 1974). In the dog, sham feeding is a very potent stimulus resulting in acid secretory rates equal to those produced by exogenous gastrin (Preshaw, 1970a). There is no obvious explanation for this apparent species difference.

After vagotomy, a 'positive' insulin test is generally believed to signify incomplete denervation of the oxyntic gland area. Insulin hypoglycaemia has recently been shown to release adrenaline, which in turn liberates gastrin (Stadil and Rehfeld, 1973; Brandsborg et al., 1975). Beta-adrenergic blockade has been found to convert insulin tests from positive to negative and to inhibit non-vagal release of gastrin by insulin-induced hypoglycaemia (Kronborg et al., 1974). Therefore, a numerically small acid response to insulin causing the test to be 'positive' according to arbitrary criteria does not necessarily imply incomplete vagotomy.

In the present study, five patients subjected to PGV displayed a substantial acid response to insulin and were judged to be incompletely vagotomised. In these patients, graded fundic distension elicited an essentially identical pattern of acid secretion before and after operation. Incompletely vagotomised patients still responded to the smallest balloon volume. Furthermore, the peak secretory fraction of $\mathrm{PAO}_{\mathrm{pg}}$ caused by fundic distension was unchanged by the operation, which means that the reductions in the peak responses to distension and pentagastrin stimulation were completely parallel. These features favour the contention that functioning vagal fibres supplying the oxyntic gland area were present in these patients. The interval between the operation and the tests of about six months may have permitted axonal regeneration or sprouting of vagal fibres (Murray, 1962). This may be illustrated by patient K.G., who early after PGV was found to be 'insulinnegative' and to have a marked reduction of the distension response (this subject is not included in the group of nine completely vagotomised DU patients); 7.5 months after operation, he had turned insulin-positive with only a slight increase in $\mathrm{PAO}_{\mathrm{pg}}$. In contrast, the peak response to fundic distension had risen considerably (from 0.93 to 2.95 $\mathrm{mmol} / 15 \mathrm{~min}$ ).

It is reasonable to assume that most vagal fibres are cut even in incomplete vagotomies. Our findings in five such patients seem to indicate that a few intact vagal fibres are sufficient to preserve the relative potency of the distension mechanism. This may support the old concept of Dragstedt et al., (1947) that even a minor intact vagal nerve may hamper the efficiency of vagotomy.

We wish to thank Miss Eva Lindberg, Mrs Annerita Toving, and Mrs Margareta Öhman for skilful technical assistance. The investigation was supported by grant no. 17 X-760 from the Swedish Medical Research Council.

\section{References}

Ambache, N. (1955). The use and limitations of atropine for pharmacological studies on autonomic effectors. Pharmacological Reviews, 7, 467-494.

Bachrach, W. H. (1962). Laboratory criteria for the completeness of vagotomy. American Journal of Digestive Diseases, 7, 1071-1085.

Bank, S., Marks, I. N., and Louw, J. H. (1967). Histamineand insulin-stimulated gastric acid secretion after selective and truncal vagotomy. Gut, 8, 36-41.

Brandsborg, O., Brandsborg, M., and Christensen, N. J. (1975). Plasma adrenaline and scrum gastrin: studies in insulin-induced hypoglycemia and after adrenaline infusions. Gastroenterology, 68, 455-460.

Debas, H. T., and Grossman, M. I. (1975). Chemicals bathing the oxyntic gland area stimulate acid secretion in the dog. Gastroenterology, 69, 654-659.

Debas, H. T., Walsh, J. H., and Grossman, M. I. (1975). Evidence for oxyntopyloric reflex for release of antral gastrin. Gastroenterology, 68, 687-690.

Dragstedt, L. R., Harper, P V., Tovee, E. B., and Woodward, E R. (1947). Section of the vagus nerves to the stomach in the treatment of peptic ulcer. Complications and end results after four years. Annals of Surgery, 126, 687-708.

Gillespie, G., Elder, J. B., Smith, I. S., Kennedy, F., Gillespie, I. E., Kay, A. W., and Campbell, E. H. G. (1972). Analysis of basal acid secretion and its relation to the insulin response in normal and duodenal ulcer subjects. New criterion for the insulin test. Gastroenterology, 62, 903-911.

Grossman, M. I. (1961). Stimulation of secretion of acid by distension of denervated fundic pouches in dogs. Gastroenterology, 41, 385-390.

Grossman, M. I. (1962). Secretion of acid and pepsin in response to distension of vagally innervated fundic gland area in dogs. Gastroenterology, 42, 718-721.

Grötzinger, U., Bergegårdh, S., and Olbe, L. (1976). Effect of fundic distension on gastric acid secretion in man. Gut, 18, 105-110.

Hollander, F. (1948). Laboratory procedures in the study of vagotomy (with particular reference to the insulin test). Gastroenterology, 11, 419-425.

Knutson, U., and Olbe, L. (1973). Gastric acid response to sham feeding in the duodenal ulcer patient. Scandinavian Journal of Gastroenterology, 8, 513-522.

Konturek, S. J., Oleksy, J., and Wysocki, A. (1968). Effect of atropine on gastric acid response to graded doses of pentagastrin and histamine in duodenal ulcer patients before and after vagotomy. American Journal of Digestive Diseases, 13, 792-800.

Kronborg, O., Pedersen, T., Stadil, F., and Rehfeld, J. F. (1974). The effect of beta-adrenergic blockade upon gastric acid secretion and gastrin secretion during hypoglycaemia before and after vagotomy. Scandinavian Journal of 
Gastroenterology, 9, 173-176.

Lim, R. K. S., Ivy, A. C., and McCarthy, J. E. (1925). Contributions to the physiology of gastric secretion. 1: Gastric secretion by local (mechanical and chemical) stimulation. Quarterly Journal of Experimental Physiology, 15, 13-53.

Magee, D. F., and Hu, C-Y. (1975). Heidenhain pouch distension as a stimulus for acid and pepsin secretion. Annals of Surgery, 182, 121-123.

Mayer, G., Arnold, R., Feurle, G., Fuchs, K., Ketterer, H., Track, N. S., and Creutzfeldt, W. (1974). Influence of feeding and sham feeding upon serum gastrin and gastric acid secretion in control subjects and duodenal ulcer patients. Scandinavian Journal of Gastroenterology, 9, 703-710.

Morrison, D. F. (1967). Multivariate Statistical Methods. McGraw-Hill: New York.
Murray, J. G. (1962). Sprouting of nerves: some consequences of vagotomy and sympathectomy. Gastroenterology, 42, 197-200.

Preshaw, R. M. (1970a). Influence of the antrum on the acid response to distension of the body of the stomach in dogs. Canadian Journal of Physiology and Pharmacology, 48, 661-669.

Preshaw, R. M. (1970b). Effect of vagotomy on the acid response to gastric distension. Canadian Journal of Phy. siology and Pharmacology, 48, 670-674.

Ross, B., and Kay, A. W. (1964). The insulin test after vagotomy. Gastroenterology, 46, 379-386.

Stadil, F., and Rehfeld, J. F. (1973). Release of gastrin by epinephrine in man. Gastroenterology, 65, 210-215.

Stempien, S. J. (1962). Insulin gastric analysis: technic and interpretations. American Journal of Digestive Diseases, 7 , 138-152. 